Abstracta Iranica Iranica

Revue bibliographique pour le domaine irano-aryen

Volume 34-35-36 | 2017

Comptes rendus des publications de 2011-2013

\title{
Hilary Gopnik, Mitchell S. Rothman. On the High Road: The History of Godin Tepe, Iran
}

\section{Rémy Boucharlat}

\section{(2) OpenEdition}

1 Journals

\section{Édition électronique}

URL : http://journals.openedition.org/abstractairanica/42135

DOI : 10.4000/abstractairanica.42135

ISSN : 1961-960X

Éditeur :

CNRS (UMR 7528 Mondes iraniens et indiens), Éditions de l'IFRI

\section{Référence électronique}

Rémy Boucharlat, « Hilary Gopnik, Mitchell S. Rothman. On the High Road: The History of Godin Tepe, Iran », Abstracta Iranica [En ligne], Volume 34-35-36 | 2017, document 119, mis en ligne le 30 juillet 2017, consulté le 28 septembre 2020. URL : http://journals.openedition.org/abstractairanica/42135 ; DOI : https://doi.org/10.4000/abstractairanica.42135

Ce document a été généré automatiquement le 28 septembre 2020.

Tous droits réservés 


\title{
Hilary Gopnik, Mitchell S. Rothman. On the High Road: The History of Godin Tepe, Iran
}

\author{
Rémy Boucharlat
}

\section{RÉFÉRENCE}

Hilary Gopnik, Mitchell S. Rothman. On the High Road: The History of Godin Tepe, Iran. Costa Mesa CA, Mazda Publishers, 2011, 379 p., ill., Index. (Bibliotheca Iranica: Archaeology, Art and Architecture Series 1)

1 Saluons la publication des résultats des importantes fouilles de Godin Tepe (1965-1973), près de Kangavar, situé sur la grande route de la Mésopotamie au Plateau iranien, à travers le Zagros central. Les résultats sont présentés de manière condensée. T. Cuyler Young, le directeur des fouilles qui publia deux importants «Interim Reports » et une série d'articles sur le site est décédé en 2006. Pour assurer la publication sans attendre plus longtemps, les deux auteurs ont rassemblé les données dans un seul volume, abandonnant l'idée première d'une publication en plusieurs ouvrages correspondant aux périodes attestées sur le site (VI à II, du Chalcolithique, $2^{\mathrm{e}}$ moitié du IV mill. à l'âge du Fer au milieu du $\mathrm{I}^{\mathrm{er}}$ mill. av. J.-C.). Publier près de dix années de fouilles en moins de 400 pages est sans doute un peu bref, mais il faut savoir que toutes les données de fouilles sont disponibles sur le site web de l'université de Toronto (Voir les données).

2 La période II, la seule concernée ici (p. 285-364), est traitée par H. Gopnik, spécialiste de l'âge du Fer qui avait consacré son doctorat à la poterie de cette période. La citadelle, qualifiée de mède, est un complexe construit de $5000 \mathrm{~m}^{2}$ environ $(120 \times 50 \mathrm{~m})$, protégé par un rempart, renforcé de tours carrées à archères sur un des longs côtés. À l'intérieur, le bâtiment le plus remarquable est une salle à colonnes $(5$ x 6 rangées de poteaux de bois sur socle de pierres plates), sans doute elle-même protégé par des tours d'angle. Une autre salle à colonnes et accolée perpendiculairement à la première, 
appartient à une seconde phase, et une autre du côté opposé est encore plus tardive. Toute la partie Est et occupée par deux rangées de salles étroites parallèles datant de deux phases postérieures. En quelques pages claires, l'A. décrit l'histoire architecturale du complexe sur plus d'un siècle, les techniques de construction, principalement la brique crue, enfin la poterie, abondante et très diversifiée dans le détail des formes, où les bols et coupes dominent, mais non dans les techniques (Common Ware à 77\%, mais aussi Fine Ware) : ce sont surtout des vases à boire et à manger, illustrant des fonctions sociales et rituelles de festivités ou cérémonies, activités que confirme l'abondance des ossements animaux.

Godin Tepe est un site majeur de l'âge du Fer, une référence, à comparer à celle de Nush-i Jan proche, partiellement contemporain de celui-ci. En effet, H. Gopnik révise la datation proposée naguère, vers le milieu du VII ${ }^{\mathrm{e}}$., en distinguant deux phases : l'occupation principale et toutes les constructions importantes, (fin IX ${ }^{\mathrm{e}}$ ?) $\mathrm{VIII}^{\mathrm{e}}$-début $\mathrm{VII}^{\mathrm{e}}$ s., comme Nush-i Jan, l'autre, très limitée, après un hiatus, une réoccupation sous forme de petites constructions dans la cour principale au $\mathrm{VI}^{\mathrm{e}} \mathrm{s}$., une occupation de fermiers et bergers. Selon H.G., le complexe de Godin et sa date illustreraient la montée en puissance des chefs locaux à partir du IX $\mathrm{e}$. (plus tard les " rois mèdes " des Assyriens), qui furent ensuite absorbés par le pouvoir central sous les rois, tel que Cyaxare, qui conduisirent les Mèdes à la conquête et la destruction de l'empire assyrien.

\section{AUTEURS}

\section{RÉMY BOUCHARLAT}

UMR 5133 CNRS-Université de Lyon 